\title{
A Response to David Temperley's Commentary
}

\author{
WILLIAM THOMSON \\ University of Southern California
}

\begin{abstract}
The author responds to points raised in David Temperley's commentary, which appeared in Vol. 1, No. 2 of Empirical Musicology Review. The response includes a discussion of strengths and limitations of atemporal models of musical perception, with particular attention to presentations such as those of Carol Krumhansl and Fred Lerdahl.
\end{abstract}

Submitted 2006 June 13; accepted 2006 June 14

KEYWORDS: perception, melody, melodic, harmony, tonality, form, structure

PROFESSOR Temperley (2006) was kind to respond with such honesty and thoroughness to my essay. I am pleased that he finds innovative elements in the Tonality Frame, despite remaining questions of clarity and parentage. He mentions two principal obstacles encountered in accepting my overall thesis. I'll respond to those and little else.

First the matter of the Tonality Frame and its temporal vs. atemporal nature. The alleged ambivalence surprises me; I can imagine no theory of music, nor any symbolic means for representing such a theory, that lacks a temporal basis. An overarching point of my essay is that music - and in capsule form melody - is a product of inseparable time/space kinetics. Let us for all times dispense with theories that impose rigid preconceptions and their symbolic grids that conveniently ignore time. They are empty rhetoric. Fred Lerdahl's "basic pitch space" and Carol Krumhansl's "key profile" are synopses of pitch probabilities derived from the "major" music of our West-European repertoire. [1] If they truly represent basic pitch space, then I must observe that the space is overpopulated, suspiciously endowed with the jewels of 7-note diatonicism-including even the infamous IV-degree of Unterklang fame.

Theories that attempt to represent atemporal essences should be shelved along with other empirically sterile dogmas. This is a principal shortcoming of the Schenkerian Ursatz: It possesses certain predetermined attributes (like descending Urlinien and harmonic foundations funded in Rameau's favorite chords). Because of these canonic a priori properties - which essentially ignore temporal dynamics or stylistic peculiarities - it lacks credibility as a synopsis of musical structure. It works reasonably well as a guide to European $18^{\text {th }}$ century music, but as a "theory of music" it is anemic.

And just those kinds of limitations are a principal cry of my essay. Music scholarship is in sore need of analytical tools that loosen the nuts and bolts of all music, not just the artifacts of our cozy 1600 1900 West-European colony. Thus the Tonality Frame.

Temperley's second principal observation relates to origins of the Tonality Frame. Is it new? Or is it merely a spin-off from Schenker's musings and/or Lerdahl's “Tonal Pitch Space?" I should hope neither; my response requires more than one simple answer.

The concept was first formulated over a half-century ago, a basic conclusion in my doctoral dissertation. I didn't call it tonality frame there. I first used that designation a decade later (1966) in Chapter 2 of Materials and Structure of Music, Vol. I. (Christ-DeLone-Kliewer-Rowell-Thomson), then as a pedagogical headstone in my Introduction to Music Reading (1965). If, as Professor Temperley suggests, the ins and outs of my description of the Tonality Frame have not "been articulated as clearly as [they] could be," he might take a look at those earlier descriptions (as well as my more recent Tonality of Music, 2001) for clarification.

If so dated, why did I supply yet another essay about the frame? A simple reason: here it is used as a tool to urge its application to melody across cultures and times, a further reminder that cognitive archetypes do prevail, whether the creator embellishes Cro-Magnon cave walls or spray-paints Los Angeles freeway signs.

Traditional conceptualizations of pitch-in-time recognize harmonic ingredients in melody of only a very special kind - a kind directly linked to the Rameau-Riemann-Schenker postulations of Harmony in music. They traffic mainly in chordal arpeggiations. For instance, Mozart's K. 332 in $F$ major begins with the clear articulation of the $F$ major triad, 1-3-5-3. As time goes by, other "chords" are outlined by its melodic figurations as well. But tonality frames view the drama of an enlarged stage. They denote 
harmonic underpinnings of a broader kind, underpinnings that persist to maintain a pitch context, the harmonic "perspective" of a protracted time span. They are tonality.

For a limited repertoire, Schenker's Ursatz does this too (even beyond the realm of what is perceptually credible!). But it does so in a way that confines as surely as it defines. By this I mean that some aspects of Schenkerian theory actually block empirical appraisals of pitch structure. [2] A simple and basic case is the Urlinie, that generalized descending line that by definition is in sync with events of the Bassbrechung. And yet, the earnest analyst must often scrape the casket's bottom to supply all the required Urlinie body parts. (Sometimes only divine fiat can turn the trick, as in Chopin's E-minor Prelude's 5-1 descent.)

And for just one more demurer, that Urlinie doesn't always seem destined to accept Schenker's decree of a 1, 3, or 5 beginning - as Allen Forte discovered in trying to fit Hoagy Carmichael's "Skylark" into the hallowed canon, finally deciding that in fact it begins on 6! [3]

So for reply \#1, the Tonality Frame is by no means a branch from the Schenkerian tree, faint similarities though it (necessarily) shares. The atemporal representations posed by Krumhansl and Lerdahl are not basic in a perceptually meaningful way; they are nothing more than statistical synopses of "most notes" found in a limited repertory of our Western World, via empirical tests that suffer procedural flaws. [4] They are atemporal predictors whose predictive merit is low in melodies from outside the Bach-Brahms orbit, melodies whose "eccentric" pitch play yields eccentric note statistics. "Mary Had a Little Lamb" confirms the "predictors admirably. The melodies of David Raksin's classic "Laura" and Alabama's "Now Your Man Done Gone" do not.

All of the illustrated frames Temperley finds inconsistent are in fact consistent: whole notes $=$ focal pitch; reduced note values $=$ pitches of lesser tonal/structural value. The frame itself always consists of pc 1, usually with conforming status of pc 7 and/or 4-that is, in melodies where the projection of truly "melodic" context is evident. After that, black noteheads represent prominent embellishing parts. All frames share these ingredients. Some represent parts of the structural mix more than others, but only in order to make clear the contextual wherewithal of a complex mix. Since I don't regard the visual representation of the Tonality Frame as some canonic Ursatz, I don't always use precisely the same notational distribution of its parts, left-to-right. They nonetheless refer to the same basic pitch dynamics.

Temperley is astute in his contrast of Lerdahl's pc hierarchy to my pitch hierarchy, but the distinction is rather beside the point. The pitches in my tonality fames are notated where they are for a very simple reason: melodies are made of specific pitches. If I were analyzing whole textures I could readily build generalized representations, drawn from combined pitch frames, of thicker wholes consisting of pitch-class frames. [5] In this sense the Tonality Frame of a full Bachian texture could be a representation by pitch-classes, a distillation for the sake of simplicity.

Finally, Professor Temperley takes umbrage with my sidelong glance at statistical approaches to structural definition, the "note-counting" methods favored by some theorists today. Let me be clear: I have nothing against such methods per se. They can yield significant information. I would only urge that bits always be counted within the bounds of recognized hierarchical probabilities, bounds that observe the interplay of pitches in time as we perceivers absorb them. And as a modeling procedure, purely statistical tallies suffer a built-in danger. Arthur Koestler addressed it many years ago with his sage observation that "Statistics are like a bikini. What they reveal is provocative. What they conceal is crucial."

So we are left with a question: If statistical correlations don't fill the bill, how do "parametric kinetics" work? One way is via the cognitive/perceptual mores we humans possess. They begin with recognition of our engrained patterns and their imposed probabilities of contextualization (like the harmonic series) [6] of pitches in time. Given any temporal prominence, the perfect $5^{\text {th }}$ of aural perception vectors in a particular "direction," not unlike the arrow of visual perception. The tonality frame is but a tiny ingredient of just one kind of "credible, testable alternative" for our use.

Prof. Temperley is right on when he observes that "there has been a notable lack of concrete proposals in this [the area of parametric kinetics] direction." Let us hope that he will begin adding to this unfunded reservoir soon. His expertise could be valuable. 


\section{NOTES}

[1] I discuss such procedural problems in the classic Krumhansl et al. study in Tonality in Music (1999, 123-127), as does David Butler (1989) in "Describing the perception of tonality in music: A critique of the tonal hierarchy theory and a proposal for a theory of intervallic rivalry."

[2] I can't improve on Gene Narmour's incisive words. As he notes in Beyond Schenkerism (1977, p. 83), a menu of pre-determined harmonic goals in the Schenkerian perspective "leads to erroneous theories of melodic structure and a weakened sense of aural comprehension - in short, to a highly impoverished theory of melody."

[3] Popular American Ballads of the Golden Era, 1925-50, 48-49.

[4] See Note \#1.

[5] And thus a simpler reduction than that of the Josquin texture, Fig. 16.

[6] Which—even in this PostMod world of ours—we can't escape!

\section{REFERENCES}

Butler, D. (1989). Describing the perception of tonality in music: A critique of the tonal hierarchy theory and a proposal for a theory of intervallic rivalry. Music Perception Vol. 6, pp. 219-42.

Christ, W., DeLone, P., Kliewer, V., Rowell, L., \& Thomson, W. (1966). Materials and Structure of Music. Englewood Cliffs, NJ: Prentice-Hall.

Forte, A. (1959). Schenker's conception of musical structure, Journal of Music Theory Vol. 3, pp. 1-30.

Forte, A. (1995). The American Popular Ballads of the Golden Era, 1924-50: A Study in Musical Design. Princeton, NJ: Princeton University Press.

Narmour, E. (1977). Beyond Schenkerism. Chicago: University of Chicago Press.

Temperley, D. (2006). Commentary on William Thomson's "Pitch frames as melodic archetypes." Empirical Musicology Review, Vol. 1 No. 2, pp. 103-5.

Thomson, W. (1952). A Clarification of the Tonality Concept. Ph.D. dissertation, Bloomington, IN: Indiana University.

Thomson, W. (1966). Introduction to Music Reading. $1^{\text {st }}$ ed. Belmont, CA: Wadsworth.

Thomson, W. (1999). Tonality in Music: A General Theory. San Marino, CA: Everett Books. 